Prosiding Seminar Nasional Teknologi Informasi dan Kedirgantaraan : Transformasi Teknologi untuk Mendukung Ketahanan Nasional, Yogyakarta, 13 Desember 2018

SENATIK 2018, Vol. IV, ISBN 978-602-52742-0-6

DOI: http://dx.doi.org/10.28989/senatik. v4i0.223

\title{
OPTIMISTIC BIAS IN TIME AND COST ESTIMATION FOR SOLAR POWER PLANT PROJECT
}

\author{
Bagus Wahyu Utomo
}

Program Studi Teknik Industri

Sekolah Tinggi Teknologi Adisutjipto

Jl. Janti, Blok R, Lanud Adisutjipto Yogyakarta

Email : baguswahyu@stta.ac.id

\begin{abstract}
Industrial environment has seen from the ability of company to meet the high requirements and expectations from consumers on quality, cost, and processing time. Experienced estimators on project tend to underestimate or pesimistic bias when assessing when project will be completed or how much it will cost for the project. Purpose of this study is to identify whether optimistic biases influence project estimation and submit proposal intervention. This study uses a solar power plant project as a case study. Respondents in this study were employees of an EPC company that was categorized as a novice and expert. Optimistic bias occurs on the accuracy of time and the cost of the respondent. In general, the accuracy of expert respondents in estimating project time and costs is more accurate than respondent novice. Intervention in this study is when estimating project time and costs should be carried out by expert category estimator.
\end{abstract}

\section{Keyword: Optimistic Bias, Estimation, Project}

\section{Pendahuluan}

Estimasi biaya pada proyek infrastruktur dilakukan pada tahap awal penerapan adalah proses yang sangat krusial. Terlepas dari keterbatasan data, ketidakpastian kondisi dan resiko yang tidak teridentifikasi sebelumnya, estimasi biaya awal selalu diperlukan untuk menyediakan berbagai biaya pembangunan proyek sesuai dengan standar kualitas yang telah di tetapkan oleh sponsor proyek[1].

Lingkungan industri saat ini dipandang dari kemampuan perusahaan tersebut memenuhi persyaratan dan harapan dari konsumen yang sangat tinggi terhadap kualitas, biaya, dan waktu pengerjaan. Untuk mencapai tujuan ini sebuah perusahaan menerapkan penjadwalan sebagai fungsi yang cukup penting. Fungsi penjadwalan kegiatan proyek dimaksudkan untuk mengatur sumber daya manusia dan teknologi secara langsung agar memenuhi persyaratan dan harapan dari konsumen[2].

Proyek-proyek konstruksi biasanya dipengaruhi oleh berbagai faktor risiko. Risiko dalam proyek konstruksi dibagi menjadi dua kategori utama, yaitu bersifat risiko internal dan risiko eksternal[3,4]. Faktor internal terdiri dari keputusan manajer, desain, pekerja, logistic, dan detail kontrak. Faktor eksternal terdiri dari hukum, politik, ekonomi, social, dan alam[5]. Estimator berpengalaman pada proyek cenderung untuk underestimate atau mengalami pesimistic bias ketika menilai kapan proyek akan selesai atau berapa banyak biaya yang dikeluarkan untuk proyek tersebut. Jika estimasi lebih baik dari aktual dinamakan optimistic bias, jika aktual lebih baik dari estimasi maka dinamakan pesimistic bias[6].

Penelitian ini menggunakan proyek pembangunan PLTS (Pembangkit Listrik Tenaga Surya) sebagai studi kasus. Energi merupakan salah satu kebutuhan utama dalam kehidupan manusia. Semakin maju suatu negara, semakin besar energi yang dibutuhkan[7]. 
Dibandingkan dengan teknologi energi terbarukan lainnya, industri PLTS adalah industri yang relatif baru dengan pengalaman operasional terbatas. Pertumbuhan yang cepat selama beberapa tahun terakhir telah menyebabkan perkembangan cepat dalam teknologi PLTS dan peningkatan skala dan kompleksitas proyek dan risiko yang terkait[8]. Dalam melaksanakan penelitian untuk mengidentifikasikan kemungkinan adanya optimistic bias pada responden novive dan expert, maka penelitian ini fokus pada keputusan diambil sesuai dengan estimasi waktu dan biaya pembangunan PLTS, responden dalam penelitian ini adalah novice dan expert dengan pengalaman di PLTS, penelitian ini menggunakan sistem tender lelang terbuka, pekerjaan proyek tersebut dapat dikerjakan oleh umum, dan dilakukan oleh badanbadan yang sudah lulus pra-kwalifikasi, dan dilakukan saat kondisi ekonomi stabil[9].

Tujuan yang ingin dicapai dalam penelitian ini adalah mengidentifikasi optimistic bias saat pelaksanaan estimasi waktu dan biaya proyek, mengajukan usulan intervensi terhadap optimistic bias untuk menghasilkan estimasi yang lebih akurat, membantu praktisi dalam mengestimasi waktu dan biaya pada proyek, dan memberikan intervensi untuk meningkatkan akurasi dalam penentuan keputusan estimasi pada proyek.

\section{Metodologi Penelitian}

Sebuah proyek adalah usaha sementara untuk membuat produk, jasa, dan hasil yang unik[10]. Estimasi waktu dan biaya proyek adalah proses peramalan untuk mendekatkan waktu dan biaya penyelesaian proyek[11]. Proses estimasi diklasifikasikan menjadi top-down dan bottom-up. Estimasi top-down biasanya dilakukan oleh manajemen senior. Manajemen senior mengestimasi berdasarkan analogi, kesepakatan kelompok, atau perhitungan matematis sederhana. Estimasi bottom-up dilakukan oleh para pekerja yang mengerjakan proyek di lapangan. Estimasi mereka berdasarkan pada perkiraan elemen yang ada pada Work Breakdown Structure (WBS).

Responden penelitian ini berasal dari karyawan di PT. XYZ yang menangani proyek PLTS di berbagai daerah di Indonesia. Responden yang dipilih adalah kategori novice yaitu karyawan dengan kualifikasi sebagai pelaksana teknis, staf departemen pemasaran dan penjualan, staf akuntansi dan keuangan, staf bagian logistik, staf bagian SDM dan umum, dan staf bagian purna jual dengan jumlah total 21 responden. Kemudian expert yaitu karyawan dengan kualifikasi sebagai project manager, engineer, dan site manager pada proyek PLTS dengan jumlah total 31 responden. Kualifikasi dari responden dalam penelitian ini di tunjukan pada Tabel 1.

Tabel 1. Kualifikasi Personil Proyek PLTS

(Sumber Dokumen Teknis Perusahaan)

\begin{tabular}{|l|l|c|}
\hline \multicolumn{1}{|c|}{ Kualifikasi } & \multicolumn{1}{|c|}{ Definisi/Tugas } & Kapasitas \\
\hline $\begin{array}{l}\text { Team } \\
\text { Meader/Project }\end{array}$ & $\begin{array}{l}\text { Team Leader/Manager Proyek adalah seseorang } \\
\text { dengan kualifikasi S1 (Elektro, Mesin, Fisika, } \\
\text { Manajemen), memiliki sertifikat keahlian Ahli Madya } \\
\text { Bidang Elektrikal, dengan pengalaman di atas 5 (lima) } \\
\text { tahun menguasai bidang pekerjaan yang ditugaskan. }\end{array}$ & Expert \\
\hline $\begin{array}{l}\text { Tenaga } \\
\text { Ahli/Engineer }\end{array}$ & $\begin{array}{l}\text { Engineer adalah seseorang dengan kualifikasi minimal } \\
\text { S1 (Elektro, Mesin, Fisika, Sipil) dengan Pengalaman } \\
\text { di atas 5 tahun menguasai bidang perencanaan Sistem }\end{array}$ & \multirow{2}{*}{ Expert } \\
& Pusat Listrik Tenaga Surya. & \\
\hline
\end{tabular}


Tabel 1. Kualifikasi Personil Proyek PLTS (lanjutan)

(Sumber Dokumen Teknis Perusahaan)

\begin{tabular}{|l|l|c|}
\hline \multicolumn{1}{|c|}{ Kualifikasi } & \multicolumn{1}{|c|}{ Definisi/Tugas } & Kapasitas \\
\hline $\begin{array}{l}\text { Site Manager / } \\
\text { Manager Lapangan }\end{array}$ & $\begin{array}{l}\text { Site Manager adalah seseorang dengan kualifikasi } \\
\text { minimal D3 (Elektro, Mesin, Fisika) dengan } \\
\text { Pengalaman di atas 5 tahun menguasai bidang } \\
\text { pekerjaan yang ditugaskan. }\end{array}$ & Expert \\
\hline Pelaksana Teknis & $\begin{array}{l}\text { Pelaksana Teknis adalah seseorang dengan kualifikasi } \\
\text { Pendidikan minimal SMK (listrik, sipil), dengan } \\
\text { pengalaman sekurang-kurangnya diatas 3 tahun } \\
\text { menguasai bidang pekerjaan yang ditugaskan. }\end{array}$ & Novice \\
\hline $\begin{array}{l}\text { Dept. Pemasaran } \\
\text { dan Penjualan }\end{array}$ & $\begin{array}{l}\text { Staf departemen pemasaran dan penjualan adalah } \\
\text { seseorang dengan kualifikasi minimal D3 (Ekonomi, } \\
\text { Manajemen, Elektro). }\end{array}$ & Novice \\
\hline $\begin{array}{l}\text { Dept. Akuntansi } \\
\text { dan Keuangan }\end{array}$ & $\begin{array}{l}\text { Staf departemen akuntansi dan keuangan adalah } \\
\text { seseorang dengan kualifikasi minimal D3 (Ekonomi, } \\
\text { Akuntansi). }\end{array}$ & Novice \\
\hline Bagian Logistik & $\begin{array}{l}\text { Bagian logistik adalah seseorang dengan kualifikasi } \\
\text { minimal SMK. }\end{array}$ & Novice \\
\hline $\begin{array}{l}\text { Bagian SDM dan } \\
\text { Umum }\end{array}$ & $\begin{array}{l}\text { Bagian SDM dan Umum adalah seseorang dengan } \\
\text { kualifikasi minimal S1 (Psikologi, Manajemen, } \\
\text { Industri). }\end{array}$ & Novice \\
\hline Bagian Purna Jual & $\begin{array}{l}\text { Bagian Purna Jual adalah seseorang dengan kualifikasi } \\
\text { minimal D3 (Ekonomi, Manajemen). }\end{array}$ & Novice \\
\hline
\end{tabular}

Variabel bebas pada penelitian ini adalah responden novice, responden expert, estimasi waktu, dan estimasi biaya, sedangkan variabel terikat adalah optimistic bias. Eksperimen menggunakan desain one shot case study (desain studi kasus sekali tes). Pola hubungan antar variabel ditunjukan pada Gambar 1.

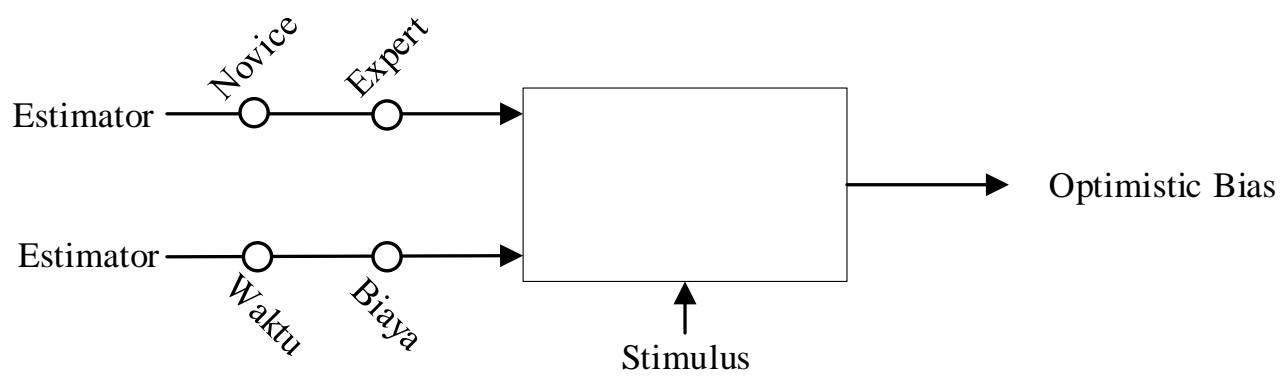

Gambar 1. Pola Hubungan Variabel Bebas dan Variabel Terikat

Kuesioner digunakan sebagai tugas kepada responden novice dan expert dalam menjawab pertanyaan-pertanyaan (item) yang terkait dengan estimasi waktu dan biaya proyek PLTS. Pilot study dilakukan untuk mengevaluasi apakah kuesioner sebagai instrumen penelitian sudah sesuai dengan tujuan penelitian. Pilot study dilakukan kepada tiga orang expert proyek PLTS yang tidak termasuk dalam responden penelitian. Evaluasi kuesioner menggunakan content validity dan face validity. 
Pengumpulan data realisasi proyek diambil dari PT. XYZ, yang terdiri dari Data waktu dan biaya riil pembangunan PLTS di Indonesia pada tahun 2018 dan data spesifikasi dan lokasi pembangunan PLTS tahun 2018. Pengumpulan data kuesioner untuk faktor Optimistic Bias adalah data estimasi waktu most likely setiap responden diambil dari nilai tengah antara durasi waktu optimistic dan durasi waktu pesimistic. Data estimasi biaya most likely setiap responden diambil dari nilai tengah antara biaya optimistic dan biaya pesimistic. Hasil estimasi waktu most likely dan biaya most likely proyek oleh responden dibandingkan dengan waktu dan biaya realisasi aktual proyek PLTS oleh peneliti.

Untuk menganalisis kemungkinan optimism bias yang terjadi, masing-masing set data estimasi waktu dan biaya most likely tersebut dikurangi dengan data waktu dan biaya aktual pengerjaan proyek, sehingga menghasilkan akurasi dari estimasi proyek. Rata-rata akurasi bernilai positif atau negatif merupakan petunjuk apakah estimasi yang dihasilkan mengalami optimistic bias atau tidak.

Intervensi akan dilakukan berdasarkan hasil dan Analisa optimistic bias. Intervensi ini dilakukan dengan memberikan saran perbaikan pada prosedur estimasi proyek dan memberikan adjustment terhadap nilai estimasi yang terbukti optimistic bias[12]. Hal ini dilakukan sebagai saran kepada pengambil keputusan di dalam tim proyek dan juga sebagai tindakan pencegahan terhadap kegagalan estimasi waktu dan biaya proyek PLTS.

\section{Hasil dan Pembahasan}

Responden pada penelitian ini terdiri dari dua kelompok yaitu novice dan expert. Kelompok novice terdiri dari Pelaksana Teknis, Dept. Pemasaran dan Penjualan, Dept. Akuntansi dan Keuangan, Bagian Logistik, Bagian SDM dan Umum, Bagian Purna Jual dengan jumlah total 21 orang. Kelompok expert terdiri dari Team Leader/Project Manager, Tenaga Ahli/Engineer, Site Manager/Manager Lapangan dengan jumlah 31 total orang.

Analisis optimistic bias dilakukan untuk melihat apakah terjadi kesalahan yang sistematis (bias) pada pengambilan keputusan pada proyek terkait waktu dan biaya. Untuk menganalisis kemungkinan optimistic bias yang terjadi, masing-masing set data estimasi waktu dan biaya tersebut dikurangi dengan data waktu dan biaya aktual pengerjaan proyek PLTS. Untuk menganalisis kemungkinan optimistic bias yang terjadi, masing-masing set data estimasi waktu dan biaya tersebut dikurangi dengan data waktu dan biaya aktual pengerjaan proyek PLTS, sehingga menghasilkan tingkat akurasi dari estimasi proyek PLTS. Secara matematis dapat dituliskan sebagai berikut:

Akurasi $(\Delta)$ estimasi waktu expert $=$ waktu estimasi expert - waktu aktual expert

Akurasi $(\Delta)$ estimasi waktu novice $=$ waktu estimasi novice - waktu aktual novice

Akurasi $(\Delta)$ estimasi biaya expert = biaya estimasi expert - biaya aktual expert

Akurasi $(\Delta)$ estimasi biaya novice $=$ biaya estimasi novice - biaya aktual novice

Analisis dilakukan dengan menguji secara statistik masing-masing set data tersebut dengan uji hipotesis mean sampel tunggal[13], kemudian dilanjutkan dengan uji z saling bebas untuk mengetahui kemungkinan adanya systematic bias dalam melakukan estimasi proyek PLTS.

Uji hipotesis mean sampel tunggal untuk analisis optimistic bias pada proyek yaitu:

$\mathrm{H}_{0}: \mu=0$, menunjukan tidak terdapat bias/kesalahan yang sistematis

$\mathrm{H}_{1}: \mu \neq 0$, menunjukan terdapat bias/kesalahan yang sistematis

$\propto=0,05_{\text {two tailed }}$ 
Tabel 2. Uji Hipotesis Mean Sampel Tunggal Akurasi Estimasi Waktu Expert

\begin{tabular}{|c|c|c|c|c|c|}
\hline Resp. & Tugas & $\mathbf{N}$ & t-hitung & t-tabel & p-value \\
\hline \multirow{2}{*}{ Expert } & Waktu & 124 & $-0,829$ & 1,979 & 0,409 \\
\cline { 2 - 6 } & Biaya & 124 & 2,599 & 1,979 & 0,010 \\
\hline \multirow{2}{*}{ Novice } & Waktu & 84 & $-5,679$ & 1,989 & 0,000 \\
\cline { 2 - 6 } & Biaya & 84 & $-2,610$ & 1,989 & 0,011 \\
\hline
\end{tabular}

Berdasarkan hasil perhitungan pada Tabel 2 nilai t-hitung akurasi estimasi waktu pada expert berada pada non rejection area dari t-tabel dan nilai p-value $>\propto\left(0,05_{\text {two tailed }}\right)$, sehingga tidak dapat menolak $\mathrm{H}_{0}$. Berdasarkan hasil perhitungan pada Tabel 1 nilai t-hitung akurasi estimasi waktu pada expert berada pada non rejection area dari t-tabel dan nilai p-value > $\propto\left(0,05_{\text {two tailed }}\right)$, sehingga tidak dapat menolak $\mathrm{H}_{0}$. Secara statistik dapat disimpulkan bahwa tidak terdapat kesalahan sistematis / bias pada data akurasi waktu di expert. Data akurasi waktu kelompok expert, waktu kelompok novice, dan biaya kelompok novice, memberikan nilai t-hitung estimasi waktu berada pada rejection area dari t-tabel dan nilai p-value < $\propto\left(0,05_{\text {two tailed }}\right)$, sehingga dapat menolak $\mathrm{H}_{0}$. Secara statistik dapat disimpulkan bahwa terdapat kesalahan sistematis/bias pada data akurasi biaya kelompok expert, waktu kelompok novice, dan biaya kelompok novice pada estimasi proyek.

Analisis selanjutnya adalah analisis uji hipotesis sampel ganda menggunakan uji z saling bebas karena data sampel berukuran besar $(n>30)$ [14]. Uji z dilakukan untuk melihat ada atau tidaknya perbedaan akurasi expert maupun novice saat melakukan estimasi waktu dan biaya. Rangkuman hasil uji $\mathrm{z}$ independen ditunjukan pada Tabel 3. Hipotesis yang digunakan dalam uji z independen yaitu:

$\mathrm{H}_{0}: \mu \_$expert $=\mu \_$novice $\rightarrow$ tidak terdapat perbedaan akurasi antara kedua kelompok data

$\mathrm{H}_{1}: \mu \_$expert $\neq \mu \_$novice $\rightarrow$ ada perbedaan akurasi antara kedua kelompok data $\alpha=0,05_{\text {two tailed }}$

Tabel 3. Uji Hipotesis Sampel Ganda Pada Akurasi Estimasi Waktu dan Biaya Proyek

\begin{tabular}{|c|c|c|c|}
\hline Variabel & z-hitung & z-tabel & Sig. $(\boldsymbol{p}$-value $)$ \\
\hline Akurasi Waktu Expert vs Novice & 3,269 & $\pm 1,960$ & $0,002<\alpha$ \\
\hline Akurasi Biaya & 3,595 & $\pm 1,960$ & $0,000<\alpha$ \\
\hline
\end{tabular}

Tabel 4. Rangkuman Hasil Perhitungan Akurasi Estimasi Waktu dan Biaya Proyek

\begin{tabular}{|c|c|c|c|}
\hline Variabel & Responden & $\mathbf{N}$ & Selisih Rata-rata \\
\hline \multirow{2}{*}{ Waktu } & Expert & 124 & $-1,78$ \\
\cline { 2 - 4 } & Novice & 84 & $-11,39$ \\
\hline \multirow{2}{*}{ Biaya } & Expert & 124 & 199.604 .202 \\
\cline { 2 - 4 } & Novice & 84 & -316.322 .204 \\
\hline
\end{tabular}


Berdasarkan Hasil perhitungan Tabel 3, nilai z-hitung pada variabel akurasi waktu dan akurasi biaya berada pada rejection area dan nilai sig. (p-value) $<\propto$, sehingga tidak dapat menerima $\mathrm{H}_{0}$. Secara statistik dapat disimpulkan bahwa terdapat perbedaan data akurasi estimasi proyek antara expert dan novice.

Berdasarkan Tabel 4, pada kolom kesimpulan tanda mutlak menunjukan jarak mean selisih terhadap nilai 0 . Nilai mean selisih waktu dari kelompok expert lebih rendah dari kelompok novice, sedangkan nilai mean selisih biaya dari kelompok expert lebih rendah dari kelompok novice. Sehingga dapat dikatakan estimasi waktu proyek kelompok expert lebih akurat dari kelompok novice dan estimasi biaya proyek kelompok expert lebih akurat dari kelompok novice.

\section{Kesimpulan}

Optimistic bias terjadi pada akurasi waktu dan biaya responden novice karena nilai estimasi waktu dan biaya responden tersebut cenderung lebih kecil jika dibandingkan dengan nilai waktu dan biaya aktualnya. Namun pada estimasi biaya responden expert mengalami underestimate. Optimistic bias terjadi pada responden novice disebabkan oleh penekanan nilai tender dari segi waktu dan biaya agar dapat bersaing dengan peserta lainnya. Underestimate terjadi pada responden expert karena memberikan estimasi biaya ekstra untuk mengantisipasi kemungkinan munculnya kejadian tidak terduga pada pelaksanaan proyek yang menyebabkan penambahan anggaran proyek.

Intervensi untuk estimasi waktu dan biaya adalah membuat estimasi waktu dan biaya proyek sebaiknya dilakukan oleh expert, adjustment untuk estimasi biaya oleh expert adalah $3,1 \%$ dari estimasi biaya, dan adjustment untuk estimasi biaya oleh novice adalah $+7 \%$ dari estimasi waktu dan $+5,4 \%$ dari estimasi biaya.

\section{Ucapan Terimakasih}

Terimakasih kepada seluruh pihak yang telah membantu kelancaran dan keberhasilan untuk penyelesaian penelitian ini.

\section{Daftar Pustaka}

[1] Xenidis, Y \& Stavrakas, E. (2012). Risk based Budgeting of Infrastructure Projects. Procedia - Social and Behavioral Sciences, 74, 478-487.

[2] Cerpa, N., Bardeen, M., Astudillo, C. A., \& Verner, J. (2016). Evaluating Different Families of Prediction Methods for Estimating Software Project Outcomes. The Journal of System and Software, 112, 48-64.

[3] Aziz, R. F ., \& Hafez, S. M. (2013). Applying Lean Thinking in Construction and Performance Improvement. Alexandria Engineering Journal, 52(4), 679-695.

[4] Sigmund, Z., \& Radujkovic, M. (2014). Risk Breakdown Structure for Construction Projects on Existing Buildings. Procedia - Social and Behavioral Sciences, 119, 894901.

[5] Ahmed, M. M., Bello, A. A., \& Idris, M. N. (2012). Natural Gas Utilization and The Nigerian Gas-To-Liquid Project: An Opportunity to End Gas Flaring. International Journal of Emerging trends in Engineering and Development, 2(2).

[6] Sharot, T. (2011). The Optimism Bias. Current Biology, 21(23), 941-945.

[7] Sunardi., \& Aji, W. S. (2017). Mikrohidro untuk Solusi Daerah Terpencil. Seminar Nasional Teknologi Informasi dan Kedirgantaraan, 3, 143-147.

[8] Shahnazari, M. R., \& Lari, H. R. (2017). Modeling of a solar power plant in Iran. Energy Strategy Reviews, 18, 24-37. 
[9] Badan Pusat Statistik. (2018). Indikator Ekonomi Agustus 2018. Jakarta. Badan Pusat Statistik Indonesia.

[10] Project Management Institute. (2013). Aguide to the Project Management Body of Knowledge. Newtown Square, Pennsylfania, USA. Project Management Institute.

[11] Larson, E. W., \& Gray, C. F. (2011). Project Management: The Managerial Process. New York. McGraw-Hill/Irwin.

[12] Orr, A. D. (2004). Advanced Project Management. London, United Kingdom. Kogan Page.

[13] Montgomery, D. C., \& Runger, G. C. (2014). Applied Statistics and Probability for Engineers, 6th ed. United States of America. John Wiley \& Sons.

[14] Blank, L. T. (1980). Statistical Procedures for Engineering, Management, and Science. Tokyo. McGraw-Hill. 